\title{
Evaluación del uso de sensores remotos para identificar manchas de crudo en áreas costa afuera del Uruguay
}

\author{
Eduardo Vasquez-Dolande $^{1^{*}}$ (D); Ethel Morales $^{2}$ (D); Marcel Achkar ${ }^{3}$
}

Forma de citar: Vasquez-Dolande, E.; Morales, E.; Achkar, M. (2021). Evaluación del uso de sensores remotos para identificar manchas de crudo en áreas costa afuera del Uruguay. Boletín de Geología, 43(2), 185-202. https://doi.org/10.18273/revbol.v43n2-2021010

\section{Resumen}

El uso de Sensores Remotos para la captura de datos de la superficie terrestre y marina constituye un área de investigación muy activa en los últimos 20 años. Una de las posibles aplicaciones es la detección de hidrocarburos en cuerpos de agua, bien sea con fines ambientales o para la prospección de posibles yacimientos petrolíferos. Desde el punto de vista geológico, en el margen continental uruguayo se localizan tres cuencas sedimentarias: Punta del Este, Pelotas y Oriental del Plata, las cuales presentan posibilidades de contener acumulaciones de hidrocarburos. En este trabajo se propone la utilización de la teledetección para la identificación de manchas de crudo u oil seeps en áreas marinas. Se evalúan las distintas técnicas de percepción remota para la detección de oil seeps. Mediante una revisión del estado del arte, se establece que los sensores activos satelitales de radar de apertura sintética (SAR), presentan mejor desempeño en la detección de crudo que los pasivos. Posteriormente, se define una metodología sencilla y replicable que comprende el preprocesamiento y procesamiento de las imágenes SAR junto a la implementación de un algoritmo de detección de crudo que ha sido ampliamente probado y de fácil implementación, como lo es el de Brekke y Solberg de 2005. Luego de validar la metodología en áreas piloto del Canal de Santa Bárbara y el Río de la Plata se procede a aplicarla en el área de estudio, de $20.101 \mathrm{~km}^{2}$, en el offshore uruguayo, obteniéndose 2 detecciones que suman 18,7 ha, aunque con bajo nivel de confianza debido a que las polarizaciones disponibles (HH-HV) no son las óptimas para la detección. De los resultados obtenidos se concluye que la metodología empleada es viable para detectar oil seeps en grandes superficies de cuerpos de agua con costos relativamente bajos.

Palabras clave: Teledetección; Hidrocarburos; Oil seeps; Radar SAR; Offshore uruguayo.

\section{Evaluation of the use of remote sensors for the identification of oil seeps in offshore areas of Uruguay}

\begin{abstract}
The use of Remote Sensors to capture data from the land and sea surface is a very active research area. One of the possible applications is the detection of hydrocarbons in bodies of water, either for environmental purposes or for the prospecting of possible oil fields. In this sense, from the geological point of view, three sedimentary basins are located on the Uruguayan continental margin: Punta del Este, Pelotas and Oriental del Plata, in which evidence of hydro-carbon accumulations has been identified. This paper proposes the use of remote sensing for the identification of oil spots or oil seeps in marine areas. The different remote sensing techniques for the detection of oil seeps are evaluated. Through a review of the state of the art, it is established that active Synthetic Aperture Radar (SAR) sensors present better performance in detecting crude oil than passive ones. Subsequently, a simple and replicable methodology is defined that includes the pre-processing and processing of SAR images together with the implementation of a crude oil detection algorithm that has been widely tested and easy to implement, as is Brekke and Solberg's 2005. After validating the methodology in pilot areas of the Santa Barbara Canal and the Río de la Plata, it is applied in the study area, of $20,101 \mathrm{~km}^{2}$, in the Uruguayan offshore, obtaining 2 detections totaling 18.7 ha, although with low level of confidence because the available polarizations (HH-HV) are not optimal for detection. From the results obtained, it is concluded that the methodology used is viable to detect oil seeps in large areas of water bodies with relatively low costs.
\end{abstract}

Keywords: Remote Sensing; Hydrocarbons; Oil seeps; SAR radar; Uruguayan offshore.

\footnotetext{
${ }_{1}^{1}$ Instituto deAgrimensura, Facultad de Ingeniería,Universidaddela República, Montevideo,Uruguay. (*)evasquez@ fing.edu.uy ${ }^{2}$ Instituto de Ciencias Geológicas, Facultad de Ciencias, Universidad de la República, Montevideo, Uruguay. ethel@ fcien. edu.uy ${ }^{3}$ Instituto de Ecología y Ciencias Ambientales, Facultad de Ciencias, Universidad de la República, Montevideo, Uruguay. achkar@fcien.edu.uy
} 


\section{Introducción}

El actual modelo de desarrollo involucra la explotación de recursos naturales renovables o no para su transformación en bienes o para la generación de energía que impulse las actividades humanas. Dentro de este modelo, el petróleo es la principal fuente de energía con un $32,89 \%$ del total (BP, 2015) y las proyecciones indican que el petróleo permanecerá como la principal fuente de energía hasta por lo menos el año 2050 (Energy Information Agency, 2019).

Además de ser la principal fuente de energía del planeta, el petróleo se constituye en uno de los elementos con mayores efectos contaminantes, en primer lugar, porque su combustión genera gases de efecto invernadero; pero también por la contaminación que genera de forma directa en los cuerpos de agua, por derrames ocasionados por el ser humano o por filtraciones naturales de crudo (oil seeps) en zonas de presencia de yacimientos.

Debido a que la búsqueda de manchas de crudo en los océanos constituye una tarea muy compleja, la utilización de sensores remotos satelitales presenta importantes ventajas, por abarcar grandes superficies a costos relativamente más bajos que la inspección por embarcaciones o aviones, y con un tiempo de revisita relativamente bajo. Además, el aumento de la cantidad de este tipo de sensores satelitales, entre los que cada vez existen más proyectos de libre acceso a los datos, como las misiones Landsat de la NASA o más recientemente los satélites Sentinel del Proyecto Copernicus de la Agencia Espacial Europea (ESA), demuestran el potencial de estos como herramientas viables para la búsqueda de manchas de crudo, bien sea con fines de conservación ambiental o de exploración petrolera.

En ese sentido, en este trabajo se evaluarán las distintas tecnologías para la detección de crudo, basadas en los Sensores Remotos tanto pasivos como activos, concentrándonos en los satelitales, y dentro de estos en los proyectos que proveen datos sin costo, para determinar cuáles son los sensores más adecuados para la detección de crudo en aguas abiertas. Se propone una metodología relativamente sencilla y replicable para la detección de manchas de crudo sobre cuerpos de agua, como lo es el algoritmo de Brekke y Solberg (2005), calibrando y validando el flujo de trabajo propuesto sobre un área piloto en la Cuenca y Bahía de Santa Bárbara en California y en el área de estudio, localizada en el offshore de Uruguay.
Este trabajo constituye un primer acercamiento académico a la utilización de sensores remotos activos para la detección de hidrocarburos en zonas marítimas del Uruguay, ya que el único antecedente conocido en el país es el estudio realizado por la empresa Infoterra Ltd para ANCAP (2011) del que, por ser información estratégica de la industria petrolera, no se disponen datos públicos aparte del mapa publicado por ANCAP (Figura 4). En este sentido, el presente trabajo busca mostrar las ventajas de dicha tecnología para incentivar a la comunidad de geo científicos del Uruguay a desarrollar más líneas de investigación en esta área del conocimiento.

\section{Marco Teórico}

La detección de hidrocarburos mediante el uso de Sensores Remotos es una metodología de trabajo relativamente nueva, en comparación con las técnicas clásicas de exploración. Esta metodología se puede dividir en la búsqueda de filtraciones de crudo en tierra y en áreas costa afuera (offshore).

Con respecto al proceso de filtraciones en las áreas offshore, diversos estudios han concluido que el crudo se filtra naturalmente desde los estratos geológicos al fondo marino y de allí a la superficie. Estas filtraciones contribuyen a aumentar la proporción de petróleo en los océanos, conformando el $46 \%$ de las descargas al mar anuales del planeta, lo que representa un estimado de 600.000 toneladas/año (National Research Council, 2003). Las mayores concentraciones conocidas de oil seeps ocurren en el Canal de Santa Bárbara en California (Quigley et al., 1999), y en el Lago de Asfalto de Trinidad en el Caribe (Landes, 1973).

El proceso posterior a la filtración del crudo en el fondo marino; es decir, el destino y persistencia del crudo en el agua de mar, son controlados por procesos físicos, químicos y biológicos que varían considerablemente en el espacio y el tiempo (Reed, 1992). Existen modelos que intentan explicar el comportamiento del petróleo en el mar, mediante la combinación de las características inherentes del crudo, como lo son solubilidad, volatilidad y reactividad y los procesos hidrodinámicos de las aguas con las que interactúan. Los principales procesos que afectan a los hidrocarburos en el mar son: meteorización, evaporación, emulsificación, disolución, oxidación y transporte (National Research Council, 2003). 
Freeman (2003) llevó a cabo un importante estudio para la identificación de microfiltraciones en Santa Bárbara (California), mediante el uso de imágenes hiperespectrales. Ese trabajo evaluó, el impacto de las microfiltraciones de hidrocarburos provenientes de yacimientos offshore en Santa Bárbara. Se determinó que las mayores concentraciones conocidas de hidrocarburos provenientes de filtraciones ocurren en el Canal de Santa Bárbara, en donde se estimó un área total de $0,9 \mathrm{~km}^{2}$ para el año 1973, que había disminuido hasta los 0,4 km² en el año 1995 debido a la explotación petrolera offshore (Quigley et al., 1999).

$\mathrm{Hu}$ et al. (2003) utilizaron datos MODIS para detectar derrames de crudo en el Lago de Maracaibo (Venezuela). La detección fue posible gracias a que la alta turbidez del agua del lago proveyó un fondo "brillante” en donde se podían observar las películas de crudo altamente absorbentes de luz. Sin embargo, en los océanos oligotróficos, el agua es siempre oscura, lo que hace muy difícil la detección de crudo en este ambiente. No obstante, Hu et al. (2009) demostraron que las imágenes MODIS capturan el resplandor del sol sobre los cuerpos de agua, por lo tanto, en los lugares en donde se aprecia dicho resplandor, es posible diferenciar las manchas de crudo del agua.

Con respecto a la detección de hidrocarburos en la superficie marina mediante el uso de Radar de Apertura Sintética (SAR), se han llevado a cabo múltiples estudios, muchos de ellos con fines comerciales impulsados por las empresas petroleras, lo que ha contribuido al surgimiento de servicios de detección de petróleo, provistos por empresas especializadas en el área.

De acuerdo con Caruso et al. (2013) la más importante demostración de la utilidad operacional de los SAR en el monitoreo de descargas marinas de petróleo ocurrió en el incidente de la Plataforma Petrolera Deep Water Horizon. El Centro de Teledetección Avanzado del Sureste Tropical (CSTARS) de la Universidad de Miami, fue comisionado por la NOAA para buscar y adquirir todas las imágenes SAR comerciales disponibles del área del desastre. Para cuando la fuga de crudo fue contenida el 15 de julio de 2010 , habían sido utilizadas más de 700 pasadas de satélites pasivos y activos y alrededor de 1.400 escenas fueron adquiridas y procesadas (Leifer et al., 2012).
Uno de los trabajos más completos publicados sobre el uso de las imágenes SAR lo constituye el Manual de Usuario de Radar de Apertura Sintética Marino publicado por la NOAA (Jackson y Apel, 2004), en donde se explica en detalle el mecanismo de las ondas de microondas de los radares SAR sobre la superficie marina, el comportamiento de los hidrocarburos y surfactantes sobre los cuerpos de agua, los principales satélites existentes y los trabajos más relevantes elaborados hasta la fecha de publicación del manual.

En resumen, las técnicas de teledetección pasiva para la detección de hidrocarburos en la superficie de cuerpos de agua presentan algunas ventajas, como su relativa facilidad de procesamiento y una mayor diversidad de sensores satelitales multiespectrales que ofrecen imágenes gratuitas; sin embargo, se encuentran fuertemente limitadas por la dificultad de diferenciar espectralmente el crudo del mar mediante las longitudes de onda incorporadas por dichos sensores (Brekke y Solberg, 2005). Adicionalmente, la imposibilidad de atravesar nubes, de capturar datos durante la noche y la ausencia de imágenes en áreas offshore restringen su utilización (Leifer et al., 2012). La teledetección activa, principalmente mediante el uso de imágenes de radar SAR, presenta grandes ventajas debido al fuerte contraste agua-crudo en condiciones adecuadas de banda, polarización y vientos, a lo que se suma la posibilidad de operar durante el día y la noche y en cualquier condición meteorológica (Jha et al., 2008), alcanzando exactitudes de detección en algunos casos superiores al 95\% (Solberg et al., 2004). Por esta razón, de acuerdo con Fingas y Brown (2018) la investigación se inclina por la utilización de los sensores activos SAR para la detección de crudo en áreas offshore.

\section{Área de estudio}

Para la realización del trabajo se seleccionó un área de $20.101 \mathrm{~km}^{2}$ localizada en el margen continental uruguayo, dentro de la Zona Económica Exclusiva (ZEE) marítima de Uruguay ( $35-38^{\circ} \mathrm{S}$ y $\left.50-55^{\circ} \mathrm{W}\right)$. Desde el punto de vista geológico, el área se localiza principalmente en la Cuenca Punta del Este, la cual limita al NW-NE con el Alto del Polonio que la separa de la Cuenca Pelotas, al S con la Cuenca Oriental del Plata y al W con el Alto del Plata, que la separa de la Cuenca del Salado en el offshore argentino (Figura 1). 


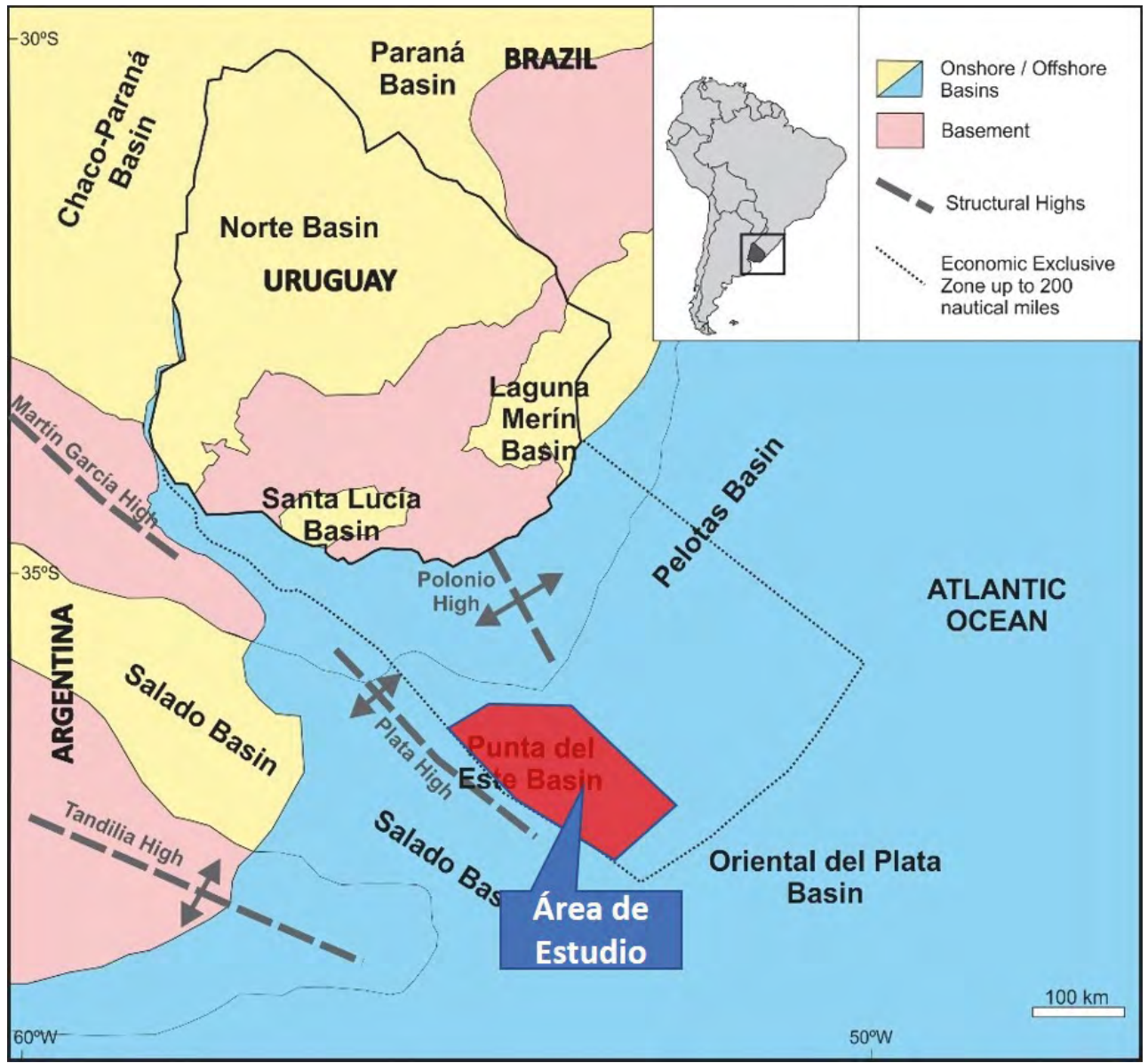

Figura 1. Ubicación del área de estudio en el contexto geológico de Uruguay. Modificado de Morales et al. (2020).

El área de estudio se ubica en una de las cuencas sedimentarias del margen continental uruguayo con potencial para contener acumulaciones de hidrocarburos (Ucha et al., 2004; Conti et al., 2017; Morales et al., 2017). Esta cuenca ha sido objeto de distintas campañas de exploración, que incluyen adquisición de datos sísmicos 2D y 3D y la perforación de 2 pozos exploratorios en el año 1976 (pozos Lobo y Gaviotín). Para la misma, se han propuesto seis sistemas petrolíferos especulativos, con base en la interpretación de datos exploratorios y el establecimiento de analogías con cuencas congéneres (Morales, 2013; Morales et al., 2017, 2020; Conti et al., 2017).

\section{Marco Geológico}

El offshore uruguayo está conformado por un conjunto de cuencas marginales formadas a partir de la fragmentación del supercontinente Gondwana y la posterior apertura del Océano Atlántico (Morales et al., 2017). Esto generó un conjunto de fosas tectónicas alargadas denominadas rifts, la mayoría de las cuales evolucionaron, a partir del Jurásico, a cuencas sedimentarias de tipo margen pasivo (Heine et al., 2013).

De acuerdo con Moulin et al. (2005) el Océano Atlántico puede ser dividido en cuatro segmentos mayores separados por grandes zonas de fracturas: el segmento Malvinas, ubicado al sur de la zona de fracturas de Falkland-Agulhas (FAFZ); el segmento Austral, entre la FAFZ y la Zona de Fracturas de Río Grande (RGFZ); el segmento Central, que se extiende al norte de RGFZ hasta la Zona de Fractura de Ascensión (AFZ); y el segmento Ecuatorial, desde la AFZ hasta la Zona de Fractura de Marathon (MFZ) (Figura 2). El margen continental uruguayo, está localizado en el segmento Austral. 

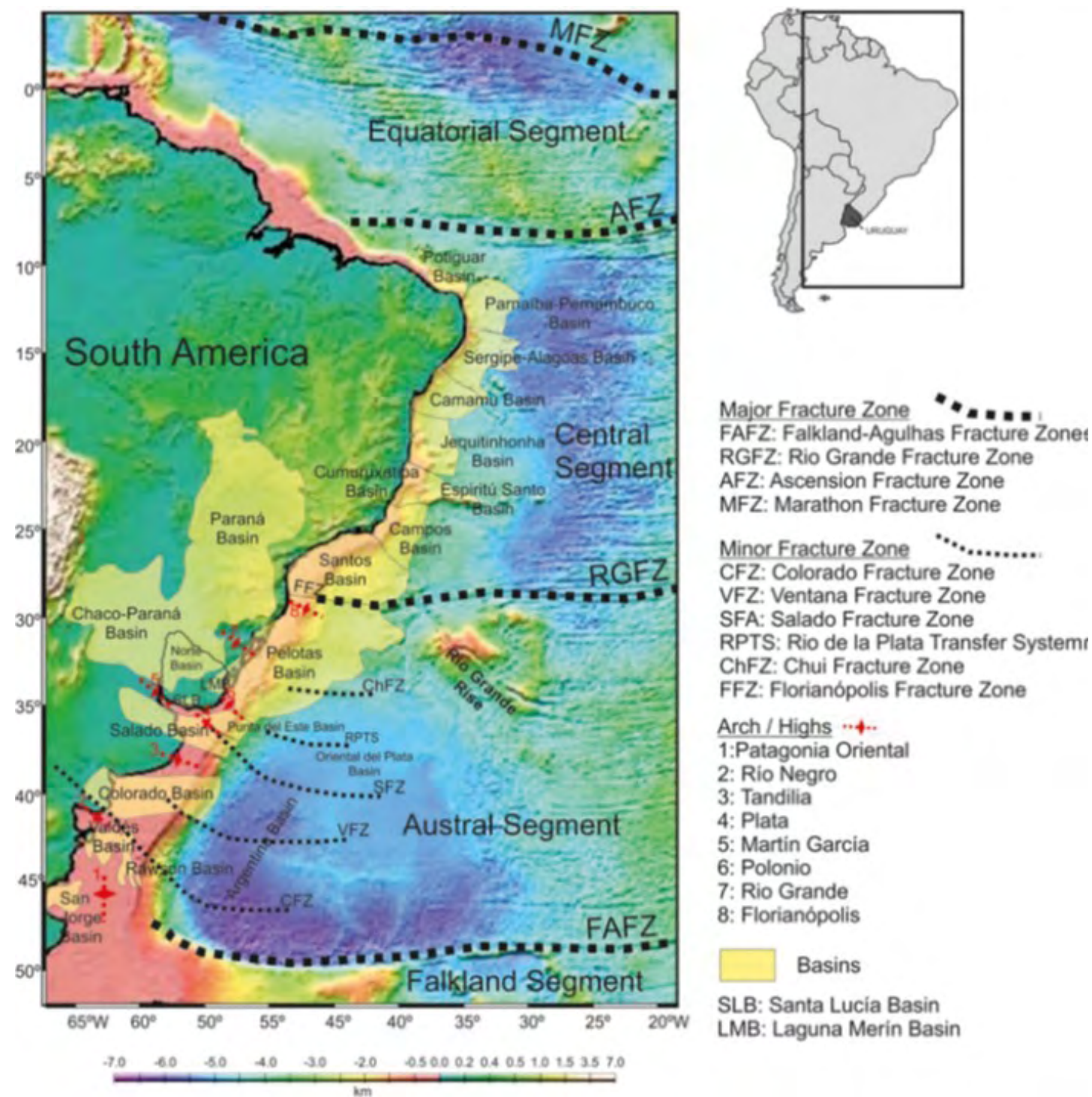

RGFZ: Rio Grande Fracture Zone

AFZ: Ascension Fracture Zone

MFZ: Marathon Fracture Zone

Minor Fracture Zone $* \cdot \cdot . . . . . . .$.

CFZ: Colorado Fracture Zone

VFZ: Ventana Fracture Zone

SFA: Salado Fracture Zone

RPTS: Rio de la Plata Transfer Systemı

ChFZ: Chui Fracture Zone

FFZ: Florianopolis Fracture Zone

Arch / Highs *.+.

1:Patagonia Oriental

2: Rio Negro

3: Tandilia

4: Plata

5: Martin Garcia

6: Polonio

7: Rio Grande

8: Florianopolis

\section{Basins}

SLB: Santa Lucia Basin

LMB: Laguna Merin Basin

Figura 2. Mapa Topográfico-Batimétrico con la superposición de cuencas onshore y offshore y elementos estructurales. Uruguay está resaltado con bordes negro. Tomado de Morales et al. (2017).

Cuencas Sedimentarias del Margen Continental

Uruguayo. En el offshore uruguayo se localizan 3 cuencas sedimentarias: la porción uruguaya de la Cuenca Pelotas, la Cuenca Oriental del Plata y la Cuenca Punta del Este (Figuras 1 y 2). Soto et al. (2011) identificaron en el margen uruguayo una zona de transferencia que denominaron "Sistema de Transferencia del Río de la Plata" (RPTS, por su sigla en inglés), localizada en el límite SW del Alto del Polonio.

\section{- Cuenca de Punta del Este}

De acuerdo con Stoakes et al. (1991) la Cuenca Punta del Este es un brazo de rift abortado con forma de embudo, siguiendo el modelo clásico de unión triple con forma de media estrella. La evolución de dicha cuenca, según estos autores, ocurrió en 3 fases: rift (Jurásico-Cretácico), sag (subsidencia térmica, durante el Cretácico) y margen pasivo (Cenozoico). Ucha et al. (2004) modifican la propuesta de Stoakes et al. (1991) y caracterizan la evolución de la cuenca en 5 fases: prerift (Paleozoico), rift I (Cretácico Temprano), rift II (Aptiano), sag (Cretácico Tardío) y margen pasivo (Cenozoico). Morales (2013) identifica 4 etapas o fases tectono-estratigráficas en la evolución de esta cuenca: prerift de edad Paleozoico, rift en el Jurásico Cretácico Inferior; transición (Hauteriviano - Aptiano) y postrift (desde el Aptiano al presente). 


\section{- Cuenca Pelotas}

La Cuenca Pelotas se desarrolla en los márgenes continentales uruguayo y brasilero, siendo una cuenca de tipo margen pasivo. Silveira y Machado (2004) realizan una subdivisión de la Cuenca Pelotas en dos subcuencas, limitadas por la terraza de Río Grande. Posteriormente, Bueno et al. (2007) utilizaron el Lineamiento de Porto Alegre como límite de separación entre estas dos subcuencas.

\section{- Cuenca Oriental del Plata}

La Cuenca Oriental del Plata está ubicada en aguas profundas y ultra-profundas del offshore uruguayo, al Sur y Sureste de las cuencas Pelotas y Punta del Este (Soto et al., 2011). Es en parte equivalente a la Cuenca Argentina, también conocida como Cuenca de la Patagonia Oriental o Cuenca de Ameghino (ANCAP, 2011). Su límite con la Cuenca Punta del Este hacia tierra firme son las cuñas de SDR. Por lo tanto, la Cuenca Oriental del Plata se desarrolla sobre corteza transicional y oceánica (Soto et al., 2011).

Potencial de acumulación de hidrocarburos en el offshore uruguayo. La búsqueda de filtraciones de hidrocarburos en el área de estudio recae sobre la presunción de existencia de acumulaciones de hidrocarburos en las cuencas sedimentarias del offshore uruguayo. En este sentido, a la Cuenca Punta del Este se le ha adjudicado cierto potencial para contener hidrocarburos (a pesar de que aún no ha registrado ningún descubrimiento), por parte de la academia uruguaya, de ANCAP (la empresa petrolera estatal encargada de la exploración de hidrocarburos) y de empresas privadas adjudicatarias de áreas de exploración en distintas rondas de licitación.

De acuerdo con el modelo tectono-estratigráfico establecido para las cuencas del offshore uruguayo (Conti et al., 2017; Morales et al., 2017; ANCAP, 2011), las potenciales rocas generadoras están asociadas a las secuencias de prerift, rift y transición (Figura 3). En las secciones sísmicas, la secuencia Barremiano-Aptiano (transición) muestra un claro carácter transgresivo, interpretado como un conjunto de depósitos marinos asociados a uno de los eventos anóxicos globales más importantes (Morales et al., 2017; Conti et al., 2017). Esta unidad, en otras cuencas del Atlántico sur, congéneres con la Cuenca Punta del Este, presenta lutitas negras ricas en materia orgánica responsables de una importante cantidad de yacimientos de hidrocarburos.

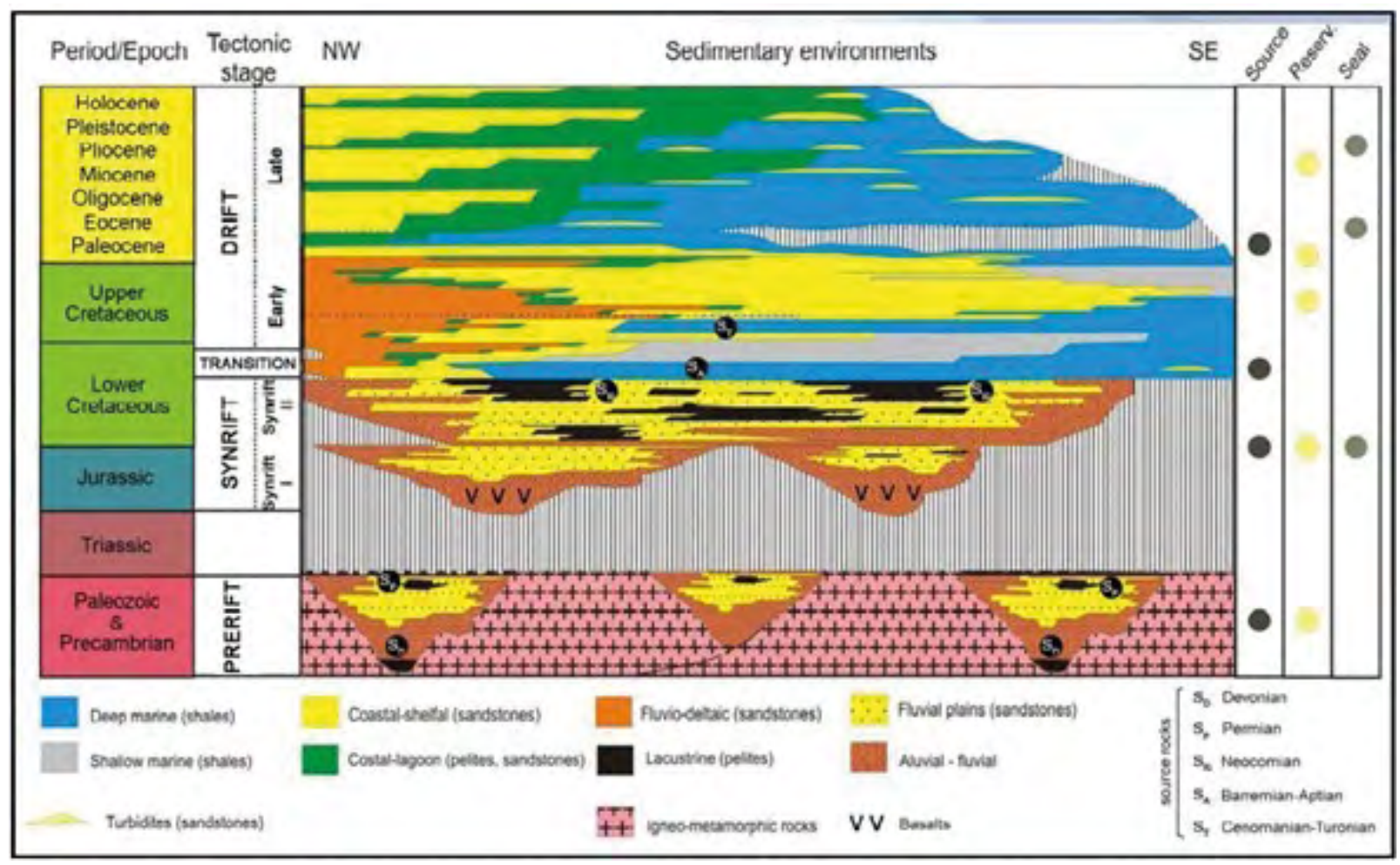

Figura 3. Componentes de sistemas petroleros especulativos para las cuencas del offshore uruguayo. Tomado de ANCAP (2011). 
Por otro lado, la Formación marina Gaviotín, de edad Maastrichtiense-Eoceno Medio provee un sello regional para las rocas productoras (ANCAP, 2011). Aunado a esto, estudios más recientes llevados a cabo por Morales et al. (2020) identifican cortejos de sistemas transgresivos, relacionados con potenciales rocas sellos para la sucesión sedimentaria de edad Cenozoica que pueden ser interpretados como depósitos marinos espesos y ampliamente extendidos, lo que restringiría la migración vertical del crudo, dificultando la carga de los reservorios Cenozoicos, así como la ocurrencia de oil seeps en el área de estudio.

El único antecedente público de identificación de oil seeps en el margen continental uruguayo se corresponde con el trabajo de ANCAP (2011). En ese trabajo se utilizaron imágenes satelitales de Radar SAR y se caracterizaron oil seeps con niveles de confianza medios y bajos (Figura 4).

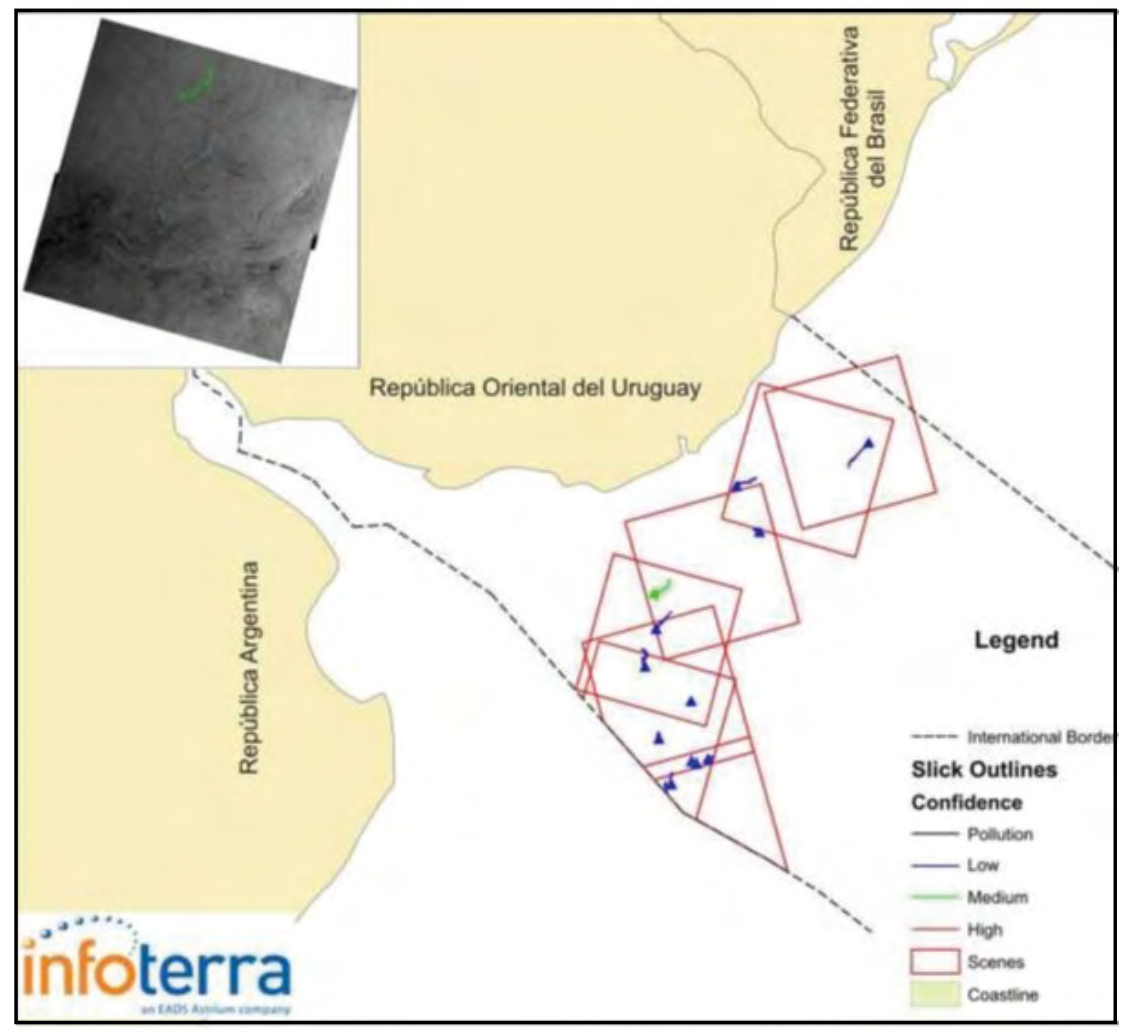

Figura 4. Identificación de oil seeps en imágenes de radar SAR en el offshore de Uruguay (ANCAP, 2011).

\section{Metodología}

Este trabajo se enfoca, en primer lugar, en la evaluación de las potencialidades de los distintos sistemas de teledetección en la identificación y discriminación de diferentes tipos de hidrocarburos presentes en las superficies marinas, como herramienta potencial en la exploración petrolera. La teledetección de hidrocarburos en cuerpos de agua podría dividirse en dos grandes tipos, en función de las características de los sensores destinados a capturar los datos:

- Teledetección con sensores pasivos: detectan radiación natural emitida o reflejada por el objeto o área circundante que está siendo observada. La luz solar reflejada es uno de los tipos de radiación más comunes medidos por esta clase de teledetección (NASA, 2012). Por esta razón, también podría llamarse teledetección óptica.

- Teledetección con sensores activos: emiten energía para poder escanear objetos y áreas, con lo que el sensor mide la radiación reflejada del objetivo. Un radar es un ejemplo de sensor activo, el cual mide el tiempo que tarda una emisión en ir y volver de un punto, estableciendo así la localización, altura, velocidad y dirección de un objeto determinado (NASA, 2012). 


\section{Teledetección Pasiva para la detección de Oil Seeps}

La investigación sobre las características de los hidrocarburos en el dominio óptico del Espectro Electromagnético (EEM) cuenta con una historia que se remonta a los años ochenta (Kudryashova et al., 1986). Se han conducido múltiples estudios sobre la reflectancia, absorción y el contraste existente entre el petróleo y el agua, encontrándose que el petróleo cuenta con una mayor reflectancia que el agua (Jha et al., 2008). Sin embargo, esta diferencia no es lo suficientemente marcada como para discriminar el petróleo del agua mediante técnicas de clasificación visual o automatizada, ya que en general las curvas de reflectancia son similares, aunque con valores ligeramente superiores para el caso del petróleo.

La amplia variabilidad de las manchas de crudo, en términos de su espesor, tipo de petróleo, procesos de degradación y las características particulares del agua en la que se encuentra, así como las condiciones de captura de las imágenes, hace que la detección de petróleo en cuerpos de agua utilizando imágenes obtenidas a través de sensores ópticos sea una tarea bastante laboriosa y que produce resultados poco deseables (Fingas y Brown, 2018).

Otro de los problemas de la teledetección en la porción óptica del espectro electromagnético son los falsos positivos ocasionados por las floraciones de fitoplancton, algas, zonas de calma e incluso por reflejos del sol sobre la superficie marina (Hu et al., 2003). Adicionalmente la disponibilidad de las imágenes ópticas se encuentra limitada por las condiciones atmosféricas, existiendo regiones marinas que por condiciones particulares presentan nubosidad durante períodos importantes de tiempo.

En conclusión, el uso de sensores remotos pasivos, principalmente satelitales, en los cuales se enfoca este trabajo, cuenta con importantes limitaciones en lo relativo a las condiciones de captura requeridas para obtener resultados aceptables. Entre estas limitaciones se encuentran la existencia de otras coberturas que podrían tener una respuesta espectral similar (lo que conduciría a falsos positivos), la necesidad de que la mancha de crudo tenga condiciones específicas para ser detectada, y por último a la poca disponibilidad de imágenes de sensores pasivos en áreas offshore, ya que su cobertura está principalmente limitada a tierra firme y zonas costeras. En virtud de lo anterior, se descarta el uso de este tipo de sensores para los fines de este trabajo.

\section{Teledetección Activa para la detección de Oil Seeps}

El principal sensor activo satelital disponible en la actualidad es el Radar de Apertura Sintética o SAR. Los sensores de Radar SAR tienen la capacidad de captar que proporción de la energía enviada por el satélite es reflejada de vuelta al sensor. La relación entre la energía emitida y la energía recibida es conocida como Coeficiente de Retrodispersión. Como las distintas coberturas del terreno o superficie interactúan de forma diferente con la señal emitida, es posible clasificar los distintos elementos o sustancias en función de la respuesta recibida.

Para la detección de hidrocarburos en la superficie del mar o cuerpos de agua, en teoría, el Coeficiente de Retrodispersión debería ser mayor para el agua que para el crudo, por lo que las manchas de este último aparecen con valores más bajos y por lo tanto más "oscuras". Sin embargo, determinar el valor de retrodispersión umbral, así como el descarte de los falsos positivos, es un reto al que se han enfrentado los investigadores durante muchos años.

De acuerdo con Alpers et al. (2017) el nivel de gris en las imágenes de radar SAR está determinado por la denominada Sección Transversal Normalizada del Radar (NRCS, por sus siglas en inglés, o $\sigma 0$ ) que representa la potencia de la señal retrodispersada. Sin embargo, valores muy bajos de NRCS en el mar, no siempre son originados por derrames de petróleo. Estos pueden ser originados por: películas naturales originadas por Plancton o peces, vientos con baja intensidad, surgencias de aguas frías, lugares con regímenes de flujo divergente, bancos de arena, aguas turbulentas, gotas de lluvia, grasa de hielo o cristales de frazil, aguas residuales, aguas de lluvias torrenciales en el mar, macroalgas flotantes, descargas de aceite por parte de barcos o aceite de pescado proveniente de las operaciones de barcos pesqueros.

Distintos autores han presentado diversas metodologías para la detección de oil seeps sobre la superficie marina. La mayoría se basan en la disminución del efecto de Bragg en aquellos lugares en donde se presentan oil seeps (Leifer et al., 2012). En general, las metodologías se pueden clasificar en técnicas de detección manual y detección automática (Brekke y Solberg, 2005), las cuales además cuentan con una fase de verificación manual de las oil seeps y la asignación de los niveles de confianza. 
Debido a que la búsqueda de oil seeps en áreas offshore puede abarcar áreas bastante grandes del mar, lo que requiere de muchas horas de inspección por parte de un especialista, el enfoque de este trabajo será la implementación de un flujo de trabajo semiautomatizado, que si bien requiere la configuración de los parámetros por parte del investigador, utiliza técnicas de detección y clasificación mediante algoritmos automatizados para la generación de los polígonos correspondientes a las manchas de crudo.

Para la selección de la metodología a utilizar para la detección de crudo, se efectuó una revisión bibliográfica de las distintas aproximaciones basadas en la utilización de imágenes SAR satelitales, así como los métodos propuestos para la detección de anomalías en imágenes en general. Con relación a esto último, Ehret et al. (2019) efectuaron una revisión de los principales métodos de detección de anomalías en imágenes, clasificándolos en cinco tipos o "familias":

- Modelos de fondo estocástico

- Modelos de fondo homogéneo

- Modelos de homogeneidad local: detección alrededor del centro

- Modelos de fondo basados en la dispersión

- Modelos de fondo de autosimilitud no local

Sin perjuicio de las potencialidades de las nuevas técnicas de detección, se decidió implementar la metodología presentada por Brekke y Solberg (2005), ya que su efectividad en imágenes SAR en cuerpos de agua ha sido ampliamente demostrada por Fiscella et al. (2000), Frate et al. (2000) y Solberg et al. (1999). Además, Marzialetti (2012) y Topouzelis y Singha (2017) confirmaron más recientemente la vigencia de dicha metodología, al utilizarla e incorporarle el paso del preprocesamiento de la imagen SAR. En la Figura 5 se presenta dicha metodología o flujo de trabajo general.

Debido a las limitaciones inherentes a este trabajo, se descartó la realización de validación en campo de las manchas de crudo. Para subsanar en parte esta carencia, se validaron y calibraron los algoritmos mediante la utilización de imágenes con manchas de crudo ampliamente identificadas, como es el caso de la Cuenca de Santa Bárbara, en California. A pesar de que las condiciones de sólidos en suspensión y temperatura varían considerablemente entre dicha zona y el offshore uruguayo, se considera que efectuar una validación de la metodología en dicha área permite contar con información sobre el desempeño de los algoritmos, sobre todo teniendo en cuenta que diversos autores definen que la variable más importante para la detección de crudo con base en imágenes de radar son los cambios en la rugosidad de la superficie marina medidos a partir del efecto de Bragg (Leifer et al., 2012; Marzialetti, 2012).

Adicionalmente, también se utilizará una imagen Sentinel 1 correspondiente a la zona del Río de la Plata en donde se encuentra identificado un derrame de crudo por parte de una embarcación infractora.

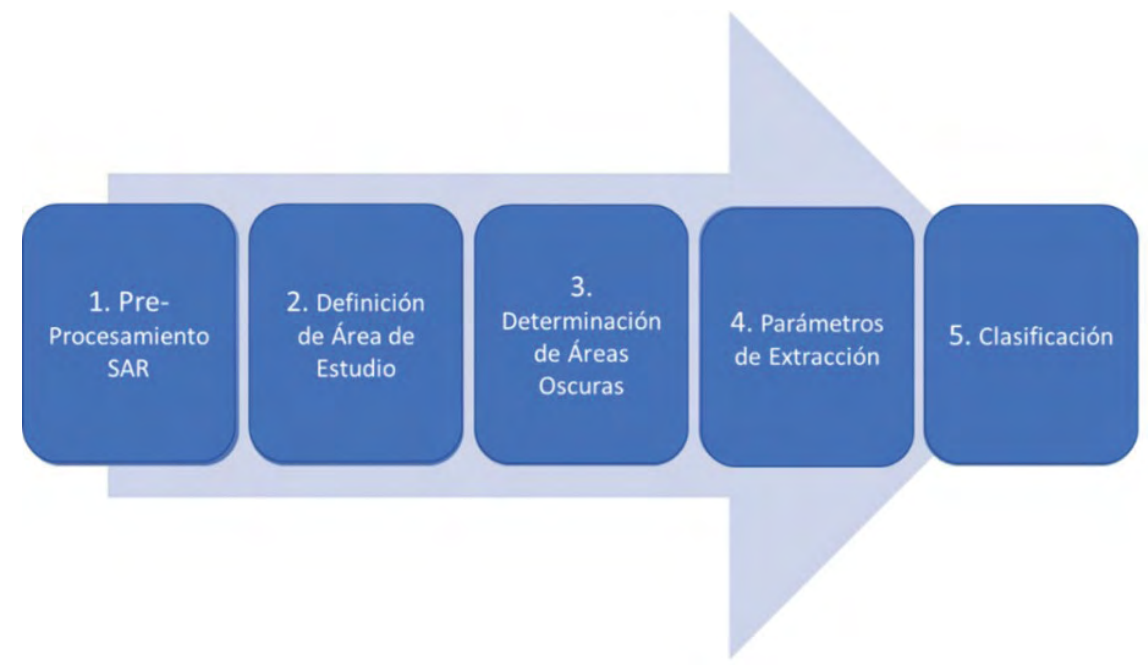

Figura 5. Metodología general para la detección de oil seeps. Adaptada de Topouzelis y Singha (2017). 


\section{Preprocesamiento SAR}

Uno de los principales retos a la hora de trabajar con imágenes de Radar SAR, consiste en el relativamente complejo preprocesamiento y procesamiento de las imágenes obtenidas. Esto se debe a que la geometría de adquisición de las imágenes es oblicua, en lugar de al nadir, como ocurre en la mayoría de los sensores pasivos. Esto genera efectos de deformación geométrica y radiométrica, como la distorsión por distancia oblicua (Slant Range Distortion), la inversión por relieve (Layover), el desplazamiento de estructuras (Foreshortening), las sombras, así como las distorsiones radiométricas por la influencia de la topografía (Podest, 2018).

El flujo de preprocesamiento de las imágenes SAR utilizado (Figura 6), es tomado de Arslan (2018), quien a su vez lo adaptó de Minchella (2016). Corresponde a un flujo habitual en imágenes SAR para corregir la distorsión geométrica y radiométrica que pueda afectar los valores de retrodispersión de las imágenes. Este flujo es compatible con las imágenes de los principales satélites utilizados: Alos-PALSAR y Sentinel 1A-1B. El software utilizado para el preprocesamiento de las imágenes SAR es el Sentinel Application Platform (SNAP), que es una aplicación modular que integra las Sentinel Toolboxes desarrolladas por Brockmann Consult, Array Systems Computing y C-S para la Agencia Espacial Europea (ESA, 2019).

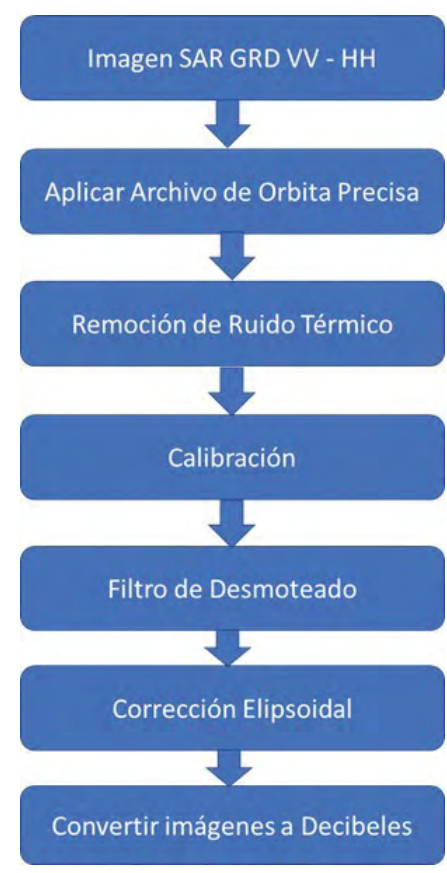

Figura 6. Flujo de trabajo de preprocesamiento de las imágenes de Radar SAR. Modificado de Arslan (2018).

\section{Determinación de Áreas Oscuras, Extracción y Clasificación}

El algoritmo de detección de hidrocarburos en cuerpos de agua desarrollado por Solberg et al. (2004) consta de tres partes principales: la detección de áreas oscuras, la extracción del área oscura y por último la clasificación de dichas áreas previamente detectadas, descritas a continuación:

Detección de áreas oscuras. La detección de áreas oscuras se hace mediante la selección de un umbral adaptativo. Este umbral se basa en un estimado del nivel típico de retrodispersión en una ventana grande, y el umbral se fija a "k" dB por debajo del valor medio local estimado del nivel de retrodispersión. Para este paso se utilizan las imágenes calibradas (Sigma0) con un filtro de desmoteado aplicado previamente.

Extracción de Áreas Oscuras. El algoritmo de Solberg et al. (2004) utiliza una mezcla de descriptores de región estándar a partir de un análisis de la imagen, así como características particulares en detección de manchas de crudo (Solberg et al., 1999).

Clasificación de las Manchas. Posterior a la detección y extracción de puntos oscuros es preciso determinar aquellos que realmente son filtraciones de crudo de los falsos positivos. El algoritmo de detección a utilizar incluye una combinación de un modelo de clasificación estadística que incorpora conocimiento previo en términos de una función de perdida y una aproximación basada en reglas (Solberg et al., 2004). El algoritmo de clasificación, a su vez, intenta replicar la forma en que un operador humano entrenado valora una posible filtración en relación con una escena completa, así como su conocimiento de la influencia de las condiciones ambientales y el comportamiento general de las manchas de crudo (Solberg et al., 1999).

\section{Resultados}

En virtud de que el área de estudio se ubica a más de $150 \mathrm{~km}$ de las costas uruguayas, resulta inviable efectuar una comprobación en campo de los resultados obtenidos mediante los algoritmos de detección de hidrocarburos utilizados. Por esta razón, se decidió utilizar dos áreas adicionales para la calibración y validación de los modelos a emplear. Dichas áreas corresponden con la filtración de crudo natural en el Canal de Santa Bárbara (California) y un sector del Río 
de la Plata, ubicado unos $100 \mathrm{~km}$ al Este de la ciudad de Buenos Aires en donde se presentan frecuentes reportes de derrames de hidrocarburos (Colombo et al., 2005).

\section{Evaluación de la Calidad de las Técnicas de Desmoteado en el Río de la Plata}

Con la finalidad de evaluar cuál método de Desmoteado tiene mejor desempeño en una imagen típica en un cuerpo de agua, se utilizó una imagen Sentinel 1-A correspondiente a la zona del Río de la Plata del 15 de mayo de 2016, con polarización VV (Figura 7).
Se aplicaron los filtros de Desmoteado de Lee Refinado, Lee Sigma, Frost y Gamma Map, con la finalidad de evaluar el desempeño de cada uno de estos en función de la reducción de la desviación estándar y del Número Estimado de Vistas (ENL, por sus siglas en inglés). En la Tabla 1, se pueden apreciar los resultados de los filtros aplicados sobre el área homogénea. El filtro con el mejor desempeño, en función de valor más alto de ENL, fue el Lee Sigma, con un ENL de 24,65 y con la desviación estándar más baja $(0,0045)$, seguido del filtro de Lee Refinado con un ENL de 10,98 y con la segunda menor desviación estándar $(0,0066)$.

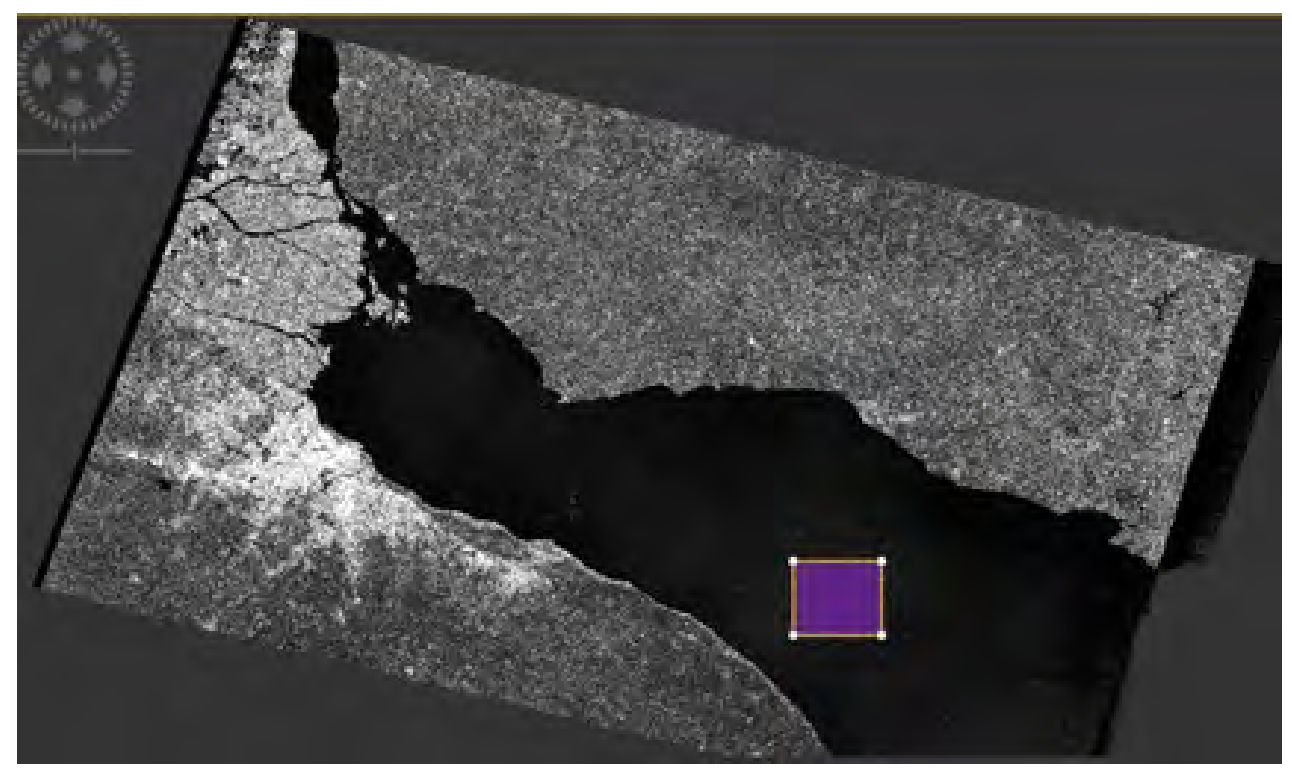

Figura 7. Imagen Sentinel 1-A del 15 de mayo de 2016 correspondiente a la zona del Río de la Plata. El modo de adquisición es Interferometric Wave en Polarización VV con ángulo de captura entre los $29,3^{\circ}$ y los $45,6^{\circ}$.

Los resultados obtenidos en la imagen de referencia permiten concluir que la utilización de un filtro de Lee Sigma con una ventana o kernel de $7 \times 7$, posterior al Multilooking de la imagen, está acorde con los requerimientos de suavizado de las imágenes para la posterior detección de crudo, ya que suaviza la imagen, reduce la desviación estándar y mantiene la media.

Tabla 1. Resultados de aplicación de distintos Filtros de Desmoteado en imagen Sentinel 1-A del 15 de mayo de 2016 correspondiente a la zona del Río de la Plata.

\begin{tabular}{ccccc}
\hline Filtro & Ventana & Media & Desviación Estándar & ENL \\
\hline Multilooking & - & 0,0222 & 0,0092 & 5,89 \\
Frost & $3 \times 3$ & 0,0222 & 0,0068 & 10,76 \\
Gamma Map & $3 \times 3$ & 0,0221 & 0,0068 & 10,61 \\
Lee Sigma & $7 \times 7$ & 0,0223 & 0,0045 & 24,65 \\
Refined Lee & $7 x 7$ & 0,0219 & 0,0066 & 10,98 \\
\hline
\end{tabular}




\section{Canal de Santa Bárbara}

La existencia de filtraciones de hidrocarburos en la costa de California y más específicamente en la Cuenca de Santa Bárbara se encuentra ampliamente estudiada por la comunidad científica, lo que se puede apreciar en los trabajos de Freeman (2003), Lorenson et al. (2009) y en el informe del National Research Council (2003) titulado "Oil in the Sea". Utilizando la cartografía generada en el trabajo de Lorenson et al. (2009), se observa que la extensión de las filtraciones de crudo estudiadas abarca desde el Norte de la ciudad de San Francisco hasta aproximadamente South Beach (Figura 8).

\section{Filtraciones de Crudo en el Canal y la Bahía de Santa Barbara, California.}

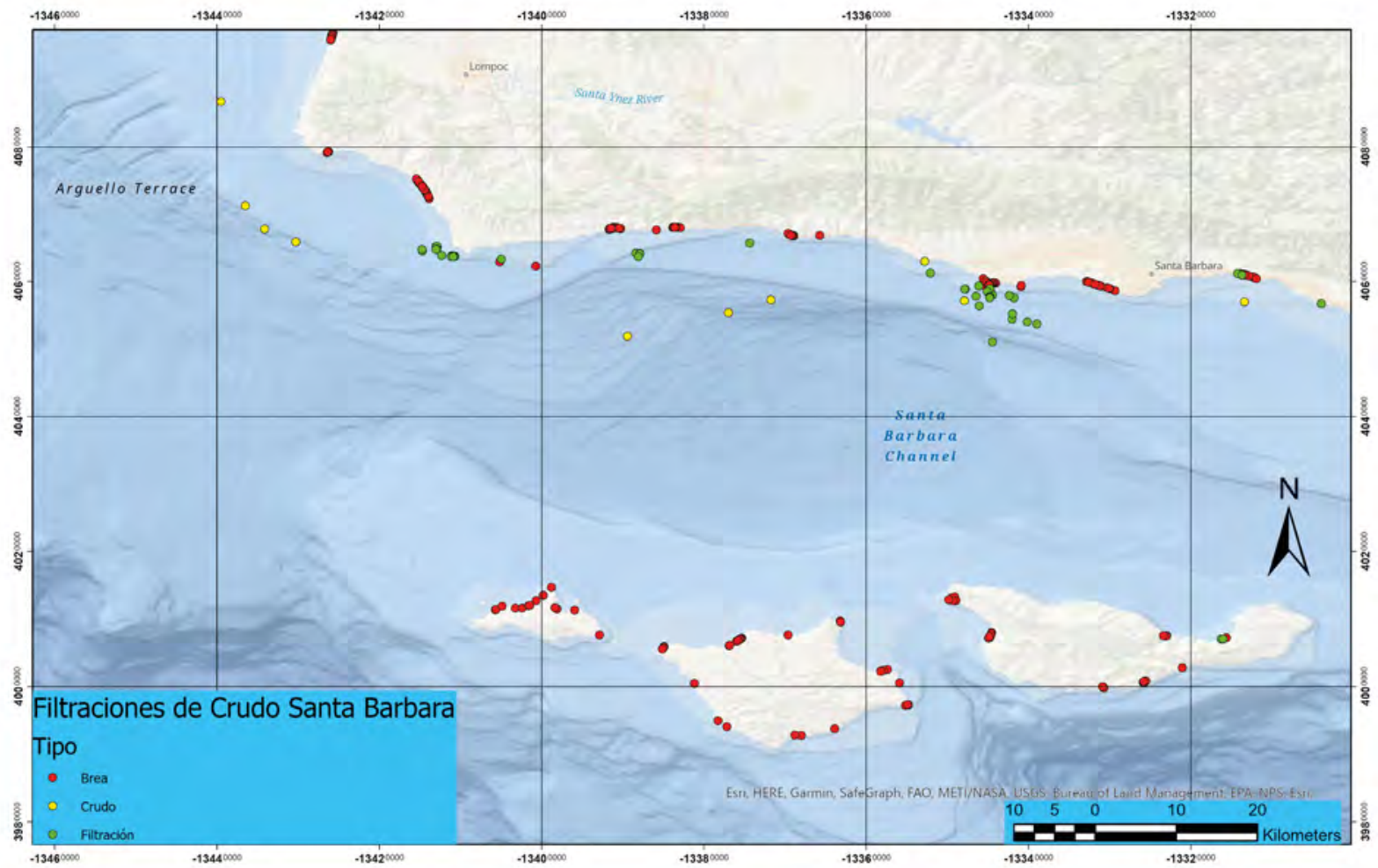

Figura 8. Mapa de localización de filtraciones de hidrocarburos y manchas de brea (puntos rojos, verdes y amarillos) en el Canal y la Bahía de Santa Bárbara en California. Modificado de Lorenson et al. (2009).

Con respecto a las imágenes utilizadas, se descargaron un conjunto de 4 imágenes de Radar SAR: 2 imágenes ALOS PALSAR de Banda L, correspondientes al 15 de abril de 2010 y el 3 de marzo de 2011 y 2 imágenes Sentinel 1 en Banda C, correspondientes al 01 de agosto de 2018 y al 20 de agosto de 2019. La selección de estas imágenes se hizo con la finalidad de poder comparar el comportamiento del algoritmo de detección de hidrocarburos en las bandas " $\mathrm{L}$ " con una longitud de onda de $23,5 \mathrm{~cm}$; y la banda " $\mathrm{C}$ " con una longitud de onda de unos $6 \mathrm{~cm}$. Debido a que el principal fenómeno que interactúa con la señal de Radar SAR sobre el mar son las ondas de Bragg, cuyo tamaño varía principalmente en función del viento, es importante evaluar en cuál de estas dos bandas existe mayor diferenciación entre la superficie del cuerpo de agua y la mancha de crudo.

Una vez preprocesada la imagen se procedió a ejecutar el algoritmo de detección de crudo de Solberg et al. (2004) incluido en el software SNAP de la ESA con los siguientes parámetros:

- Máscara de tierra firme: mediante el modelo de elevación SRTM de la NASA con una resolución de 3 segundos del arco ( $\sim 90$ metros/pixel)

- Polarizaciones: VV y VH

- Tamaño de la ventana de fondo: 61 pixeles

- Umbral de cambio: $2 \mathrm{~dB}$

- Tamaño mínimo del Cluster: $0,1 \mathrm{~km}^{2}$ 
Para la imagen del 01 de agosto de 2018 en polarización VVsedetectaron un totalde 240 polígonos confiltraciones de crudo con una superficie promedio de 16,7 has por mancha de crudo y un área total de $40,17 \mathrm{~km}^{2}$; mientras que la detección en la polarización $\mathrm{VH}$ arrojó como resultado 65 polígonos con una superficie promedio de 24,3 ha y un área total de $15,8 \mathrm{~km}^{2}$ (Figura 9). En ambas detecciones se observan falsos positivos en las áreas cercanas a la costa, debido al efecto de la reducción de la profundidad sobre la rugosidad de la superficie marina, por lo que el efecto de Bragg no aplica a dichas áreas. En la detección con polarización $\mathrm{VH}$ al igual que la $\mathrm{VV}$, se detectaron de forma correcta filtraciones de crudo asociadas a plataformas petroleras, de acuerdo con la base de datos de Lorenson et al. (2009); sin embargo, la mayoría de las filtraciones naturales documentadas por dicho autor no fueron detectadas por la polarización $\mathrm{VH}$, mientras que en la detección de la polarización VV si fueron detectadas.

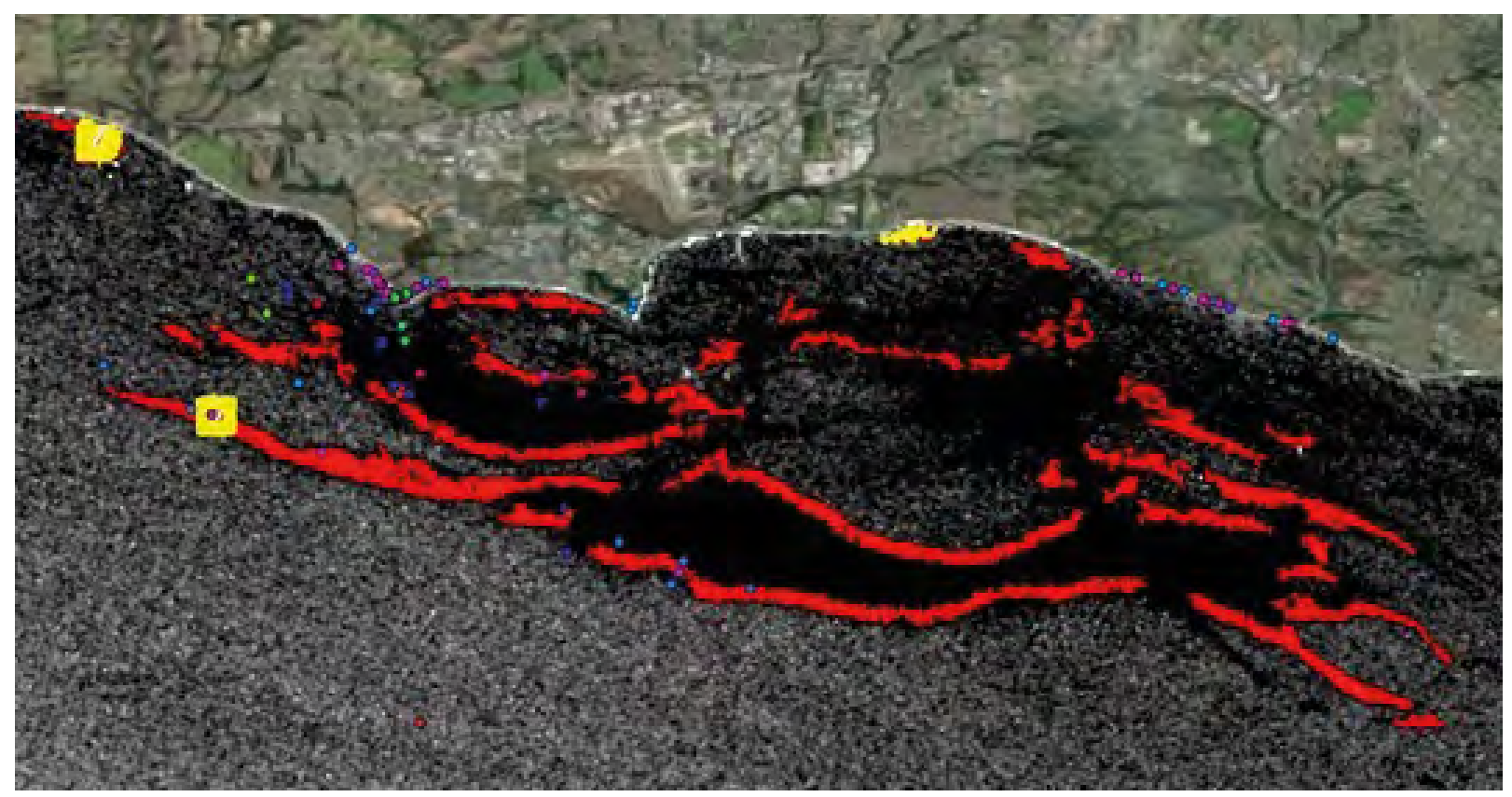

Figura 9. Detalle de diferencia de detección de hidrocarburos con imagen Sentinel 1 del primero de agosto de 2018 entre polarización VV (rojo) y VH (amarillo). Nótense los cuadrados amarillos correspondientes a falsos positivos alrededor de plataformas petroleras.

Otro fenómeno observado en la detección de crudo en la imagen con polarización VV es que se detectó aparentemente el borde de las manchas de crudo de gran extensión y no el polígono completo. Esto se debe a que el tamaño de la pluma de la mancha entra en conflicto con el parámetro del "tamaño de la ventana de fondo", siendo este último muy pequeño por lo que no se detectan los cambios más allá del cuadrado de 61 pixeles establecido. Para comprobar dicha afirmación se ejecutó el algoritmo con una ventana de mayor tamaño (200 pixeles) para la polarización VV y con el mismo umbral de $2 \mathrm{~dB}$, comprobándose que con una ventana de mayor tamaño se delinea de forma más precisa toda la mancha de crudo y no solamente los bordes de esta.

Con respecto a la imagen del 20 de agosto de 2019, en polarización $\mathrm{VV}$ y parámetros por defecto se detectaron un total de 378 polígonos con filtraciones de crudo con una superficie promedio de 12,62 ha por mancha de crudo y un área total de $47,71 \mathrm{~km}^{2}$; al ejecutar la detección con una ventana de 200 pixeles y un umbral de $2 \mathrm{~dB}$ se detectaron 720 polígonos con una superficie media de 21,45 ha y un área total de $154,5 \mathrm{~km}^{2}$. Con base a estos resultados se puede afirmar que para el caso de las imágenes Sentinel 1, la determinación de una ventana de búsqueda de mayor tamaño conduce a una mejor detección de la superficie de grandes manchas de crudo.

La ejecución del algoritmo de detección de crudo con las imágenes ALOS PALSAR en banda L con polarización $\mathrm{HH}$ con fecha de adquisición del 15 de abril de 2010 y 03 de marzo de 2011, arrojó resultados bastante pobres tanto con los parámetros por defecto, como con la ventana móvil de 200 pixeles. 


\section{Area de estudio en el offshore uruguayo}

Para la ejecución del algoritmo de detección de crudo para determinar la presencia de oil seeps en el área de estudio, el primer paso consistió en la búsqueda de las imágenes de radar SAR disponibles, principalmente enfocado en fuentes de libre acceso y gratuitas. Al excluir el borde de la grilla terrestre de captura de las imágenes Sentinel 1, se obtuvieron un conjunto de 4 imágenes Nivel 1 GRD, correspondientes a una captura en modo IW del 27 de noviembre de 2017 con polarización HH+HV. De estas imágenes se seleccionaron dos que cubren casi la totalidad del área de estudio: la 20171127T222056 y la $20171127 T 222121$.

\section{Procesamiento y Detección de Crudo del Área de}

Estudio. Posterior a la descarga de las imágenes, se procedió a efectuar la cadena de Preprocesamiento a dichas imágenes. Luego de efectuar el filtro de Speckle Lee-Sigma con ventana $7 \times 7$ se consiguió un valor de ENL de 9,3 para la imagen 20171127T222056 y un valor ligeramente inferior de 7,9 para la imagen 20171127T222121 en polarización HH. Mientras que para la polarización HV se obtuvo un ENL de 13,1 para la imagen $20171127 \mathrm{~T} 222056$ y 31,8 para la imagen $20171127 T 222121$.

El siguiente paso, previo a la ejecución del algoritmo de detección de crudo fue la determinación de las velocidades del viento al momento de la captura de las imágenes, mediante la herramienta de "Wind Field Estimation" del software SNAP. Previamente se había establecido que para la banda "C", los valores óptimos de viento para el algoritmo de detección de crudo deberían estar entre $2-14 \mathrm{~m} / \mathrm{s}$ (Solorza y Panozzo, 2018). Al ejecutar la estimación del viento para la imagen 20171127T222056 se obtuvieron vientos en el rango de $3,4-20 \mathrm{~m} / \mathrm{s}$, con una media de $12,6 \mathrm{~m} / \mathrm{s}$ y una desviación estándar de 4,077. Con respecto a la imagen 20171127T222121, las condiciones de viento fueron ligeramente mejores, con vientos entre los 2,1 y $20 \mathrm{~m} / \mathrm{s}$, pero con una media de $10,10 \mathrm{~m} / \mathrm{s}$ y una desviación estándar de 4,3.

Una vez corregidas las imágenes radiométrica y geométricamente, y evaluada la calidad de dichas correcciones, se procedió a ejecutar el algoritmo de detección de crudo de Solberg et al. (2004) con los parámetros óptimos previamente definidos:
- Polarización: HH y HV

- Ventana de búsqueda: 200 pixeles

- Umbral de detección: $2 \mathrm{~dB}$

- Tamaño mínimo de Cluster: $0,1 \mathrm{~km}^{2}$

Luego de procesar las dos imágenes 20171127T222121 y $20171127 \mathrm{~T} 222056$, en ambas polarizaciones (HH $\mathrm{HV})$, se obtuvieron los siguientes resultados:

- En la imagen 20171127T222121 (norte del área de estudio) en polarización $\mathrm{HH}$ se detectó un polígono con un área total de 10,3 ha, mientras que en polarización HV la detección no arrojó ningún resultado.

- En la imagen 20171127T222056 (sur del área de estudio) en polarización HH se detectó un polígono con un área total de 8,4 ha, mientras que en polarización $\mathrm{HV}$ se detectó un polígono de 423 ha.

- Se efectuó una comparación de las detecciones de oil seeps con las obtenidas por estudios previos llevados a cabo por ANCAP (2011) y no se observó correlación entre las detecciones de ANCAP y las obtenidas en este trabajo (Figura 10).

- Ambas detecciones en polarización HH se encuentran localizadas fuera del área de estudio. La primera a $6 \mathrm{~km}$ del límite noreste del polígono y la segunda a $40 \mathrm{~km}$ del límite sur (Figura 10).

- Se ejecutó el algoritmo de detección variando los parámetros de ventana de búsqueda a 100 pixeles y umbral de detección a 1,5 dB; sin embargo, no hubo modificaciones de consideración en los resultados obtenidos.

\section{Discusión}

A partir de la revisión bibliográfica y de antecedentes se analizaron las distintas fuentes de captura de datos por percepción remota, tanto mediante sensores activos como pasivos, determinando que el desempeño de los sensores activos, particularmente los radares SAR, es superior a los sensores pasivos para la detección de manchas de crudo sobre la superficie marina.

Al analizar los costos de adquisición y la disponibilidad de imágenes, se estableció que los sensores satelitales, representan la mejor opción para efectuar estudios preliminares en grandes superficies. 


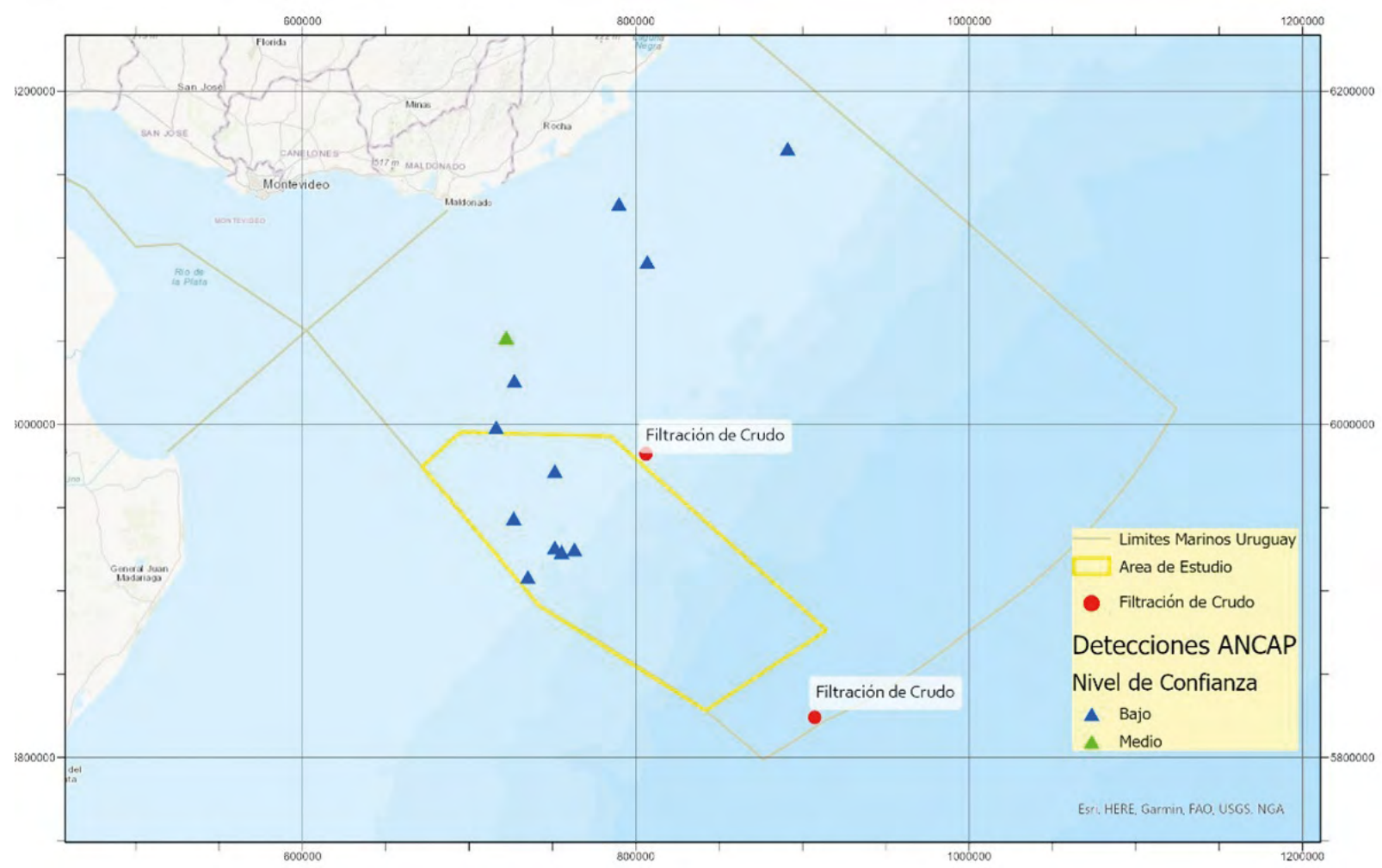

Figura 10. Comparación de las detecciones obtenidas en este trabajo (puntos rojos) con las de ANCAP (2011).

Se estableció el flujo de preprocesamiento más adecuado para las imágenes de radar SAR, principalmente para los productos Nivel 1 en Ground Range Detected (GRD) o Single Look Complex (SLC). También se determinó que el filtro de desmoteado más adecuado para las imágenes sobre superficies marinas es el Lee-Sigma con una ventana de 7x7 (Tabla 1) y se validó con una imagen Sentinel 1 en la zona del Río de la Plata.

El flujo de trabajo establecido en la metodología (Figura 8) fue calibrado y validado mediante la utilización de imágenes Sentinel 1 y ALOS-PALSAR en la zona con las mayores filtraciones de crudo del mundo: el canal y la Bahía de Santa Bárbara, en las costas de California. Determinándose la banda "C" como la banda satelital más adecuada para la detección de crudo, así como la polarización VV como la que presenta mejor contraste entre el agua y la mancha de crudo.

Con respecto a los resultados obtenidos al ejecutar el algoritmo para la detección de crudo en el área de estudio con imágenes Sentinel 1 en polarización HH y $\mathrm{HV}$, se detectaron 2 "manchas" en las imágenes: una de 10,3 ha en el NE del área de estudio y otra de 8,4 ha al SE.

\section{Conclusiones}

Los resultados obtenidos son consistentes con las conclusiones presentadas por Morales et al. (2020) con relación a las dificultades encontradas en las cuencas del offshore uruguayo para la migración vertical del crudo debido a la carencia de estructuras como, por ejemplo, fallas, que conecten rocas generadoras Cretácicas con rocas reservorios Cenozoicas y por tanto que también permitan filtraciones en la superficie marina. Sin embargo, la no identificación de oil seeps en este trabajo no puede ser tomado como conclusivo del potencial exploratorio de las cuencas del margen continental uruguayo, ya que la base de datos utilizada presentó limitaciones importantes.

La metodología presentada es una primera aproximación al tema realizado en Uruguay, y constituye una propuesta viable, tanto técnica como económicamente para la realización de estudios exploratorios orientados a la explotación petrolera. También surge a partir de esta propuesta metodológica todo un campo de investigación relacionado a la detección de manchas de crudo ocasionadas por derrames de embarcaciones, oleoductos o plataformas petroleras. 


\section{Agradecimientos}

Los autores quieren agradecer en primer lugar al Programa de Desarrollo de las Ciencias Básicas (PEDECIBA), así como a las Facultades de Ciencias e Ingeniería de la Universidad de la República (UDELAR) por el apoyo brindado para la realización de este trabajo.

\section{Referencias}

Alpers, W.; Holt, B.; Zeng, K. (2017). Oil spill detection by imaging radars: Challenges and pitfalls. International Geoscience and Remote Sensing Symposium, Fort Worth, USA. https:// doi.org/10.1109/IGARSS.2017.8127258

ANCAP. (2011). Regional Geology: Offshore Uruguayan Basins. E\&P ANCAP.

Arslan, N. (2018). Assessment of oil spills using Sentinel 1 C-band SAR and Landsat 8 multispectral sensors. Environmental Monitoring and Assessment, 190(11). https://doi.org/10.1007/s10661-018-7017-4

BP. (2015). BG Statistical Review of World Energy. BP.

Brekke, C.; Solberg, A. (2005). Oil spill detection by satellite remote sensing. Remote Sensing of Environment, 95(1), 1-13. https://doi.org/10.1016/j. rse.2004.11.015

Bueno, G.; Zacharias, A.; Orebro, S.; Supetino, J.; Falkenhein, F.; Martins-Neto, A. (2007). Bacia de Pelotas. Boletim de Geociências da Petrobras, 551559.

Caruso, M.; Migliaccio, M.; Hargrove, J.; Garcia-Pineda, O.; Graber, H. (2013). Oil spills and slicks imaged by synthetic aperture radar. Oceanography, 26(2), 112-123.

Colombo, J.; Barreda, A.; Bilos, C.; Cappelletti, N.; Demichelis, S.; Lombardi, P.; Migoya M.C; Skorutka C.; Suarez, G. (2005). Oil spill in the Río de la Plata estuary, Argentina: 1. Biogeochemical assessment of waters, sediments, soils and biota. Environmental Pollution, 134(2), 277-289. https:// doi.org/10.1016/j.envpol.2004.02.032

Conti, B.; Perinotto, J.; Veroslavsky, G.; Castillo, M.; de Santa Ana, H.; Soto, M.; Morales, E.
(2017). Speculative petroleum systems of the southern Pelotas Basin, offshore Uruguay. Marine and Petroleum Geology, 83, 1-25. https://doi. org/10.1016/j.marpetgeo.2017.02.022

Energy Information Agency. (2019). International Energy Outlook. US Department of Energy.

ESA. (2019). ESA EduSpace. http://www.esa.int/ SPECIALS/Eduspace_ES/SEMZ3YD3GXF_0.html

Ehret, T.; Davy, A.; Morel, J.M.; Delbracio, M. (2019). Image anomalies: A review and synthesis of detection methods. Journal of Mathematical Imaging and Vision, 61(5), 710-743. https://doi. org/10.1007/s10851-019-00885-0

Fingas, M.; Brown C. (2018). A review of oil spill remote sensing. Sensors, 18(1). https://doi. org/10.3390/s18010091

Fiscella, B.; Giancaspro, A.; Nirchio, F.; Pavese, P.; Trivero, P. (2000). Oil spill detection using marine SAR images. International Journal of Remote Sensing, 21(18), 3561-3566. https://doi. org/10.1080/014311600750037589

Frate, F.; Petrocchi, A.; Lichtenegger, J.; Calabresi, G. (2000). Neural networks for oil spill detection using ERS-SAR data. IEEE Transactions on Geoscience and Remote Sensing, 38(5), 22822287. https://doi.org/10.1109/36.868885

Freeman, H. (2003). Evaluation of the use of hyperspectral imagery for identification of microseeps near Santa Barbara, California. Project Report Master, West Virginia University.

Heine, C.; Zoethout, J.; Muller, R.D. (2013). Kinematics of the South Atlantic rift. Solid Earth, 4, 215-253. https://doi.org/10.5194/se-4-215-2013

Hu, C.; Li, X.; Pichel, W.; Muller-Karger, F. (2009). Detection of natural oil slicks in the NW Gulf of Mexico using MODIS imagery. Geophysical Research Letters, 36(1). https://doi. org/10.1029/2008GL036119

Hu, C.; Muller-Karger, F.; Taylor, C.; Myhre, D.; Murch, B.; Odriozola, A.; Godoy, G. (2003). MODIS detects oil spills in Lake Maracaibo, Venezuela. EOS, Transactions, 84(33), 313-319. https://doi.org/10.1029/2003EO330002 
Jackson, C.; Apel, J. (2004). Synthetic Aperture Radar Marine User's Manual. National Oceanic and Atmospheric Administration (NOAA).

Jha, M.; Levy, J.; Gao, Y. (2008). Advances in remote sensing for oil spill disaster management: Stateof-the-Art sensors technology for oil spill surveillance. Sensors, 8(1), 236-255. https://doi. org/10.3390/s8010236

Kudryashova, G.; Obraztsov, Y.; Opekan, A.; Perminov, N.; Protasov, Y. (1986). Optical properties of liquid dielectrics in the ultraviolet, visible, and near infrared regions of the spectrum. Journal of Applied Spectroscopy, 43(4), 1108-1113. https:// doi.org/10.1007/BF00662325

Landes, K. (1973). Mother nature as an oil polluter. AAPG Bulletin, 57(4), 637-641. https:// doi.org/10.1306/819A430E-16C5-11D7$8645000102 \mathrm{C} 1865 \mathrm{D}$

Leifer, I.; Lehr, W.; Simecek-Beatty, D.; Bradley, E.; Clark, R.; Dennison, P.; Hu, Y.; Matheson, S.; Jones, C.; Holt, B.; Reif, M.; Roberts, D.; Svejkovsky, J.; Swayze, G.; Wozencraft, J. (2012). State of the art satellite and airborne marine oil spill remote sensing: Application to the BP Deepwater Horizon oil spill. Remote Sensing of Environment, 124, 185-209. https:// doi.org/10.1016/j.rse.2012.03.024

Lorenson, T.; Hostettler, F.; Rosenbauer, R.; Peters, K.; Dougherty, J.; Kvenvolden, K.; Gutmacher, C.; Wong, F.; Normark, W. (2009). Natural offshore oil seepage and related tarball accumulation on the California coastline-Santa Barbara Channel and the Southern Santa Maria Basin; source identification and inventory. Reston: U.S. Geological Survey.

Marzialetti, P. (2012). Monitoreo de derrames de hidrocarburos en cuerpos de agua mediante técnicas de sensado remoto. Tesis de Maestría, Universidad Nacional de Córdoba, Córdoba, Argentina.

Minchella, A. (2016). ESA SNAP-Sentinel-1 training course. Oxfordshire: Harwell: Satellite Applications Catapult - Electron Building.

Morales, E. (2013). Evolução tectônica e estratigráfica das bacias da margem continental do Uruguai.
Tesis, Universidade Estadual Paulista Júlio de Mesquita Filho, Rio Claro, Brasil.

Morales, E.; Chang, H.; Soto, M.; Santos-Corrêa, F.; Veroslavsky, G.; de Santa Ana, H.; Conti, B.; Daners, G. (2017). Tectonic and stratigraphic evolution of the Punta del Este and Pelotas Basins (offshore Uruguay). Petroleum Geoscience, 23(4), 415-426. https://doi.org/10.1144/petgeo2016-059

Morales, E.; Conti, B.; Soto, M.; Viera-Honegger, B. (2020). Risks inherent in the Cenozoic stratigraphic plays in basins of the Uruguayan continental margin. Marine and Petroleum Geology, 112. https://doi.org/10.1016/j.marpetgeo.2019.104072

Moulin, M.; Aslanian, D.; Olivet, J.L.; Contrucci, I.; Matias, L.; Géli, L.; Klingelhoefer, F.; Nouzé, H.; Réhault, J.P.; Unternehr, P. (2005). Geological constraints on the evolution of the Angolan margin based on reflection and refraction seismic data (ZaiAngo project). Geophysical Journal International, 162(3), 793-810. https://doi. org/10.1111/j.1365-246X.2005.02668.X

Musé, P.; Sur, F.; Cao, F.; Gousseau, Y.; Morel, J. (2006). An A Contrario Decision Method for Shape Element Recognition. International Journal of Computer Vision, 69(3), 295-315. https://doi.org/10.1007/s11263-006-7546-0

NASA. (2012). Earth Science Remote Sensing. https://earthobservatory.nasa.gov/features/ RemoteSensing/remote_08.php

National Research Council. (2003). Oil in the Sea III: Inputs, Fates and Effects. The National Academies Press.

Podest, E. (2018). ARSET: Applied Remote Sensing Training. https://arset.gsfc.nasa.gov/disasters/ webinars/intro-SAR

Quigley, D.; Hornafius, J.; Luyendyk, B.; Francis, R.; Clark, J.; Washburn, L. (1999). Decrease in natural marine hydrocarbon seepage near Coal Oil Point, California, associated with offshore oil production. Geology, 27(11), 1047-1050. https:// doi.org/10.1130/0091-7613(1999)027<1047:DIN MHS $>2.3 . \mathrm{CO} ; 2$

Reed, M. (1992). State-of-the art summary: Modeling of physical and chemical processes governing 
fate of spilled oil. ASCE Workshop on Oil Spill Modeling. Charleston.

Silveira, D.; Machado, M. (2004). Bacias sedimentares brasileiras: Bacia de Pelotas. Série Bacias Sedimentares ano 6, 67.

Solberg, A.; Brekke, C.; Solberg, R.; Husoy, P.O. (2004). Algorithms for oil spill detection in Radarsat and ENVISAT SAR images. International Geoscience and Remote Sensing Symposium, Anchorage, Alaska. https://doi. org/10.1109/IGARSS.2004.1370264

Solberg, A.; Storvik, G.; Solberg, R.; Volden, E. (1999). Automatic detection of oil spills in ERS SAR images. IEEE Transactions on Geoscience and Remote Sensing, 37(4), 1916-1924. https:// doi.org/10.1109/36.774704

Solorza, R.; Panozzo, M. (2018). Tecnicas de Procesamiento Digital en Teledetección SAR. Instituto de Altos Estudios Espaciales Mario Gulich.

Soto, M.; Morales, E.; Veroslavsky, G.; de Santa Ana, H.; Ucha, N.; Rodriguez, P. (2011). The continental margin of Uruguay: Crustal architecture and segmentation. Marine and Petroleum Geology,
28(9), 1676-1689. https://doi.org/10.1016/j. marpetgeo.2011.07.001

Stoakes, F.; Campbell, C.; Cass, R.; Ucha, N. (1991). Seismic stratigraphic analysis of the Punta del Este Basin, offshore Uruguay, South America. AAPG Bulletin, 75(2), 219-240. https://doi.org/10.1306/0C9B278B-1710-11D7$8645000102 \mathrm{C} 1865 \mathrm{D}$

Topouzelis, K.; Singha, S. (2017). Oil spill detection using space-borne Sentinel-1 SAR imagery. In: M. Fingas (eds). Oil Spill Science and Technology (pp. 387-402). 2nd edition. Gulf Professional Publishing. https://doi.org/10.1016/B978-0-12809413-6.00006-0

Ucha, N.; de Santa Ana, H.; Veroslavsky, G. (2004). La Cuenca Punta del Este: geología y potencial hidrocarburífero. En: G. Veroslavsky, M. Ubilla, S. Martínez (eds.). Cuencas sedimentarias de Uruguay: geología, paleontología y recursos naturales: Mesozoico (pp. 173-192). UR. FC. DIRAC; SUG.

Fecha de recibido: 14 de septiembre de 2020

Fecha de aprobado: 30 de marzo de 2021 